\title{
Práticas de Inovação Como Ferramenta de Desenvolvimento Para Micro e Pequenas Empresas em Porto Alegre, RS
}

\section{Innovation Practices as a Development Tool For Micro and Small Businesses in Porto Alegre, RS}

\author{
Vanessa Bolico da Silva ${ }^{1}$, Micheline Machado Teixeira ${ }^{1}$ \\ ${ }^{1}$ Universidade de Passo Fundo, UPF, Brasil \\ Correspondência: Vanessa Bolico da Silva. Endereço: Av. Brasil Leste, 285, São José, Passo Fundo, RS CEP \\ 99052900. Tel.: 5554 3316-8100. E-mail: vanessab-silva@ hotmail.com
}

Recebido: 07 de março de 2017 Aceito: 12 de Agosto de 2017 Publicado: 31 de outubro de 2017

DOI: http://dx.doi.org/10.21714/1679-18272016v14n2.p393-400

\begin{abstract}
Resumo
A inovação é considerada fundamental para empresas do segmento turístico, organizações estas que estão inseridas em ambientes altamente instáveis e dinâmicos de competição, onde cada vez mais os clientes buscam diferenciação nos serviços oferecidos. Nesse contexto este estudo tem como objetivo analisar os tipos de inovações que podem ser encontradas em pequenas e médias agências de viagens na cidade de Porto Alegre, Rio Grande do Sul. Trata-se de uma pesquisa descritiva, exploratória, com natureza qualitativa e como método utiliza o estudo de casos múltiplos. Os dados foram coletados através de entrevistas e observações aplicadas aos gestores. Os principais resultados demonstram uma maior ocorrência de inovação de serviço, de processo, organizacional e marketing. Além de existir uma boa compreensão dos questionados acerca do processo de inovação, observou-se que a preocupação com a inovação, onde está representa um desafio no cotidiano organizacional das agências de viagens estudadas, que buscam ofertar novos serviços para manter-se no mercado.
\end{abstract}

Palavras-chave: Turismo; Inovação; Ferramenta de desenvolvimento; Gestão Estratégica.

\begin{abstract}
Innovation is considered to be fundamental for companies in the tourism segment, organizations that are inserted in highly unstable and dynamic environments of competition, where more and more customers seek differentiation in the services offered. In this context, this study aims to analyze the types of innovations that can be found in small and medium-sized travel agencies in the city of Porto Alegre, Rio Grande do Sul. This is a descriptive, exploratory research with a qualitative nature and as a method Multiple case study. Data were collected through interviews and observations applied to managers. The main results demonstrate a greater occurrence of service, process, organizational and marketing innovation. In addition to having a good understanding of respondents about the innovation process, it was observed that the concern with innovation, where it is a challenge in the daily organizational of the travel agencies studied, who seek to offer new services to stay in the market.
\end{abstract}

Keywords: Tourism; Innovation; Development tools; Strategic Management.

Esta obra está licenciada sob uma Licença Creative Commons Attribution 3.0

\section{Introdução}

A inovação pode ser considerada uma constante no mundo globalizado, é possível observar que a cada dia é disponibilizado no mercado um número maior de produtos e serviços. Porém, a inovação não é uma realidade recente, está presente no contexto histórico mundial, e através dela muitos setores econômicos se desenvolveram. O Turismo é um desses setores econômicos, e atualmente um dos mais relevantes em todo o mundo (ORGANIZAÇÃO MUNDIAL DO TURISMO, 2012).

Uma característica essencial da inovação é sua capacidade de proporcionar crescimento econômico e de adicionar vantagem competitiva para a empresa, no mercado em que atua. Assim, destacam Tidd, Bessant e Pavitt (2008) a inovação pode ser considerada como algo que agregue valor social ou riqueza, gerando ganhos para a empresa que a pôs em prática. Entretanto, embora a inovação seja considerada essencial para os pequenos negócios, o estudo da inovação nessas empresas é controverso, pois enquanto alguns autores defendem que a 
http://www.revista.ufpe.br/gestaoorg

inovação seria um privilégio restrito às grandes empresas (SCHUMPETER 1982; GALBRAITH, 1956), outros afirmam que são as pequenas empresas as que possuem maior capacidade inovadora (ZORTEA-JOHNSTON; DARROCH; MATEAR, 2011; NATÁRIO; COUTO; SOUZA, 2010; LAFORET; TANN, 2006; CHRISTENSEN, 2001).

De acordo com o Manual de Oslo (OCDE, 2006) as PME's encaram uma série de outras barreiras que inviabilizam o desenvolvimento de atividades inovativas, como a dificuldades de acesso a financiamento, a falta de mão de obra qualificada para desenvolver as atividades de inovação, ausência de infraestrutura, carência de informação acerca das tecnologias ou mercados necessários para desenvolver uma inovação, além da dificuldade de encontrar parceiros apropriados para projetos conjuntos de inovação.

A atividade turística está passando por mudanças cada vez mais intensas, as quais se processam em um ritmo acelerado (BENI, 2003). Diante disso, as organizações pertencentes ao setor turístico estão buscando maneiras diversas de adquirir vantagens competitivas que lhes possibilitem se diferenciar de seus concorrentes (RUSCHMANN; SOLHA, 2003). Assim, o grande desafio para a atividade turística é oferecer produtos e serviços inovadores, que ampliem o lucro e desenvolvam ainda mais a atratividade e a competitividade das organizações.

Cabe ressaltar que o estudo da inovação no turismo se mostra pertinente em razão do papel desempenhado pela atividade no desenvolvimento econômico e social. De acordo com a Organização Mundial do Turismo (2012), o turismo é uma das atividades econômicas que mais cresce, sendo responsável por 5\% do Produto Interno Bruto (PIB) mundial e $30 \%$ da exportação de serviços globais. Além disso, a atividade turística é responsável pela geração de milhões de empregos. Em 2011, gerou 255 milhões de empregos diretos e indiretos, o que corresponde a um em cada doze postos de trabalho criados (WORLD TRAVEL \& TOURISM COUNCIL, 2013). No Brasil, o cenário não é diferente, segundo dados do Ministério do Turismo (2014), o setor de turismo contribui com $9,2 \%$ do PIB no país, o que equivale a $\mathrm{R} \$ 443,7$ bilhões. Além disso, o setor foi responsável pela geração de 8,5 milhões de postos de trabalho no ano 2013 (EMBRATUR, 2014).

Diante do exposto, este estudo tem como objetivo central analisar as tipologias de inovações implementadas em agências de viagens de pequeno e médio porte. Caracteriza-se como sendo de natureza qualitativa, de propósito exploratório e descritivo, por meio da coleta de dados através de entrevistas com gestores responsáveis por três empresas de agências de viagens de pequeno e médio porte localizadas na cidade de Porto Alegre, Rio Grande do Sul. Foi adotado, neste estudo, um modelo conceitual, tomando como referência os tipos de inovação adotada pela Organização para a Cooperação e o Desenvolvimento Econômico (2006). Em relação à tipologia de inovação proposta pela OCDE, as inovações adotadas por uma empresa podem ser classificadas em quatro tipos: inovação de serviço, inovação de processo, inovação organizacional e, inovação de marketing.

\section{Conceito de Inovação}

A invenção sempre esteve presente na sociedade, todos os novos produtos foram inventados para facilitar o dia a dia, porém há uma diferença entre invenção e inovação. De acordo com Perez (2004) invenção é a criação de um novo produto ou processo, sendo que esta descoberta ocorre dentro da própria ciência. Inovação, por sua vez, é um feito econômico, é o mercado que decidirá se irá aceitar ou não esta criação. É importante ressaltar, ainda, que uma inovação só poderá se transformar em um fenômeno global se houver a difusão em massa desta nova tecnologia. Segundo Smith (2000) a inovação é fundamental para a competitividade entre as organizações e não constitui um fenômeno marginal, uma vez que é nela que se apoia o crescimento econômico em nível nacional. Grande parte das inovações traz um fluxo contínuo de mudanças incrementais, quer dizer, melhorias sucessivas em produtos ou processos que já estão à disposição das pessoas. Além das inovações incrementais existem também as inovações radicais, aquelas que introduzem no mercado um novo produto ou processo.

Segundo Perez (2004) as inovações radiais são um ponto de partida, que serve de início para novas trajetórias técnicas, pode ser introduzida a qualquer momento e é capaz de desenvolver novas indústrias. A inovação é um processo coletivo e sistêmico que envolve diferentes agentes de mudança como fornecedores, distribuidores, consumidores, entre outros, em muitas situações, a inovação está ligada à mudança tecnológica. Com relação a esta afirmativa Mokyr (1990) destaca que a mudança tecnológica na maioria das vezes apareceu como consequência de um processo sistemático de pesquisa e desenvolvimento. Mas, de acordo com Rosenberg (2006), a evolução desta mudança é inseparável da história da própria civilização.

Toda inovação possui um ciclo de vida de acordo com Perez (2009) ela aparece lentamente, no início, quando produtores, designers, distribuidores e consumidores se familiarizam com os novos processos, rápida e intensamente ela se transforma em um design dominante até chegar à maturidade. Mas é importante ressaltar que a maturidade não significa necessariamente a morte de uma tecnologia, neste caminho, podem ser inseridos novos usos ou abordagens que fazem com que esta inovação continue vigente. 


\subsection{Inovações no Segmento Turístico}

Segundo Gorni, Dreher e Machado (2009) o investimento em inovação torna-se essencial para o desenvolvimento das atividades turísticas, onde as organizações devem buscar a diferenciação na qualidade dos serviços e maior eficiência. No setor turístico, destaca Alves (2011) que inovações podem ocorrer por meio de ações diversas, como desempenho superior (best-in-class), estilo e design su $\neg$ periores, produtos e serviços multipropósitos, inovações de fronteira (on-the-edge), produtos e serviços de luxo, mar $\neg$ cas populares para o mercado de massa, serviço excepcional, maiores confiabilidade e durabilidade, conveniência, canais de distribuição únicos e preço diferencial (lower price). Além disso, de acordo com estudo realizado por Firmino (2007) a inovação no turismo pode incluir oferta de produtos e serviços novos ou melhorados, a elevação da qualidade, apostar nos recursos humanos e na aprendizagem, e na satisfação dos novos desejos do cliente, além de novos destinos turísticos e a utilização de novas tecnologias.

Álvares e Lourenço (2011) por sua vez, destacam que a inovação no setor turístico pode ocorrer por intermédio da potencialização de atrativos naturais culturais de um destino turístico. Nesse sentido, o estudo realizado pelas autoras, nas cidades de Ouro Preto e Salvador, indicou que a inovação em turismo ocorreu por meio da revitalização de atrativos turísticos das cidades. Para Fitzsimmons e Fitzsimmons (2005) outra forma de inovar no turismo está associada à adoção de ferramentas de tecnologia da informação (TI), segundo os autores, pode proporcionar vantagens diversas para as empresas, como a criação de barreira à entrada de concorrentes por meio de iniciativas para fidelizar e gerenciar o relacionamento com os seus clientes, a maximização dos lucros por meio da utilização de tecnologias de informação em tempo real com foco nas operações, possibilitando o atendimento a um número crescente de clientes.

Embora existam diversas possibilidades para inovar no turismo, segundo Mattsson, Sundbo e Jensen (2005) porém, os investimentos apresentam certa desvantagem em relação a outras empresas do setor de serviços. Desvantagem que pode estar associada ao fato das inovações em turismo serem relativamente fáceis de imitação principalmente aquelas em que os processos de primeira linha são altamente visíveis, e o nível de tecnologia é baixo. Além disso, há uma série de outros fatores que limitam a inovação na atividade turística, como: baixos investimentos em pesquisa e desenvolvimento, escassez de recursos, falta de confiança e cooperação entre empresários do turismo, baixos níveis de educação e formação de pessoal, alta rotatividade, salários baixos e turnos de trabalho não convencionais (WEIDENFELD; WILLIAMS; BUTLER, 2010).

Hjalager (2010) destaca que a atividade turística vem demonstrando ao longo do tempo uma importante capacidade de inovação e criatividade. Capacidade esta que segundo Ottenbacher (2007) proporciona às organizações do setor não apenas condições para sobreviver, mas também são determinantes para sua estabilidade e alcance do lucro no longo prazo, pois ao gerar produtos turísticos inovadores e especializados, as empresas do setor turístico poderão atrair demanda intencional e diferenciar seus serviços. Assim, a inovação cria um diferencial no mercado e possibilita o alcance de vantagem competitiva, pois os clientes/turistas preocupam-se em valorizar o dinheiro de que dispõem para o lazer, buscando novas experiências e uma gama de produtos e serviços sofisticados e criativos (PANOSSO NETTO; MAZARO, 2011).

\section{Metodologia}

O estudo caracteriza-se como exploratória descritiva, de caráter qualitativo, na medida em que foram adotadas técnicas de recolhimento e análise de dados, visando gerar resultados a partir dos significados dos elementos que caracterizam o fenômeno estudado. Na pesquisa qualitativa, o pesquisador tem uma visão holística do fenômeno estudado, facilitando a identificação dos múltiplos fatores envolvidos no fenômeno, bem como a exploração de contradições e paradoxos (CRESWELL, 2009).

Esta pesquisa adotou o método de estudo de casos múltiplos. Esse método foi considerado o mais indicado para o estudo, pois permite uma melhor compreensão do fenômeno, considerando-se que, ao se analisar mais de um caso, é possível obter maior profundidade e riqueza analítica, segundo Yin (2001), possibilitando a geração de resultados mais convincentes, sendo o estudo, por consequência, considerado mais robusto. Em relação ao critério de escolha dos casos, foram selecionados três casos de agências de viagem de pequena e média dimensões por meio do critério da tipicidade, visto que foram escolhidas empresas de forma intencional em razão do seu porte.

A utilização de mais de uma fonte de evidência garante maior qualidade aos estudos de caso, pois proporciona o desenvolvimento e a investigação de vários aspectos em relação ao mesmo fenômeno, gerando resultados mais convincentes e apurados (YIN, 2001). Dessa forma, visando garantir a qualidade deste estudo, utilizaram-se três fontes de evidência: entrevistas, análise documental e observações.

A coleta de dados por meio de entrevistas ocorreu com base um roteiro de entrevista semiestruturado que foi aplicado aos proprietários das agências de viagens. Em relação à análise documental, foram obtidos documentos, 
como: folhetos e folders, além de informações obtidas nos sites das empresas objeto deste estudo. Assim, durante a realização de entrevistas, foram observados os tipos de inovação implementados nas agências de viagens. Os dados deste estudo foram analisados qualitativamente por meio da análise de conteúdo, a qual consiste em um conjunto de técnicas para análise de diálogos, que visa obter, por meio de procedimentos sistemáticos e objetivos de descrição do conteúdo das mensagens, indicadores que permitam a inferência de conhecimentos relativos às condições de produção/reprodução das mensagens.

\section{Análise dos Resultados}

\subsection{O caso das agências de viagens 1,2 e 3}

O primeiro caso analisado é da Agência de Viagens classificada como agência 1. Para análise foram coletadas informações no site da empresa o que possibilitou conhecer os serviços oferecidos pela empresa. Além disso, utilizou-se da técnica de observação, para captação de informações complementares. A agência de viagens 1, foi fundada em 2004 e possui 10 colaboradores, quantidade está que permite sua classificação como uma empresa de pequeno porte. A empresa oferece serviços como, cruzeiros, venda de passagens aéreas, reservas de hotéis, excursões, aluguel de veículos. O proprietário entrevistado e gestor da Agência 1, possui 40 anos, com nível de estudos superior em Administração. Com relação aos tipos de inovações encontradas, implementadas na agência, foram destacados os quatro tipos de inovação, conforme a classificação da OCDE (2005): inovações de serviço, de processo, organizacional e de marketing.

No que se refere às inovações de serviço implementadas nos últimos anos na agência, o entrevistado destacou que passou a oferecer o serviço de atendimento on-line, que permite ao cliente solicitar orçamentos, tirar dúvidas, ou pedir informações através do site da agência, nesse sentido, o cliente não necessita ir até a agência ou contatar atendimento telefônico o que gerou economia financeira e de tempo. Também, foi incluída no site da agência uma nova funcionalidade que permite aos clientes pesquisar preços de passagens aéreas e tarifas de hotéis. O empresário destacou ainda outros serviços inovadores disponíveis no site, como: conversão de câmbio, fuso horário e minidicionário, em que o cliente pode visualizar algumas expressões básicas em idiomas diversos. Outro serviço inovador é a sala vip, que está sendo montada no aeroporto a fim de oferecer um suporte aos clientes da agência. Nessa sala, os clientes da agência terão acesso à internet, além de poderem desfrutar de lanches e serviço de massoterapia.

Com relação à inovação por processo, o empresário destacou que inicialmente foram realizadas mudanças no processo de vendas, com a aquisição de um sistema moderno, onde o vendedor lança os dados do ciente e da venda, a partir desses dados são emitidos relatórios diários que permitem o acompanhamento das vendas realizadas na agência. Além disso, com esse novo sistema, os recibos, que antes eram emitidos manualmente, passaram a ser gerados automaticamente, onde o vendedor lança os dados dos clientes, o que permite formar um banco de dados, também são lançados no sistema a forma de pagamento, gerando a comissão da agência e do vende $\neg$ dor em cada venda realizada.

Questionado acerca das inovações na gestão, o entrevistado relatou que uma inovação organizacional foi à implantação de reuniões mensais na agência. Segundo ele na fase inicial do negócio não haviam reuniões, pois achava que, pó se tratar de uma empresa de pequeno porte, bastava conversar com os funcionários diante da ocorrência de algum problema. No que se refere às inovações de marketing adotadas pela agência, o empresário relatou que há cerca de quatro anos implantou um festival de prêmios, que ocorre uma ou duas vezes por ano. Nesse festival, são sorteados prêmios como passagens aéreas, hospedagens em hotéis e resorts e ipads. Além dessas promoções, o entrevistado destacou ainda que começou a utilizar o Facebook como forma de divulgar a agência, seus serviços e os pacotes promocionais. Outra inovação de marketing relacionada à divulgação está associada à utilização da televisão para fazer a divulgação da agência, visto que anteriormente as únicas mídias utilizadas eram rádio e site.

O segundo caso analisado é da agência de viagens classificada como agência 2, fundada no ano 2005 e que possui 18 colaboradores. A partir da análise de documentos, como folhetos, folders e informações contidas no site da agência, verificou-se que os serviços oferecidos incluem, vendas de passagens aéreas nacionais e internacionais, pacotes turísticos, hospedagens, organizações de grupos para congressos, eventos, seguro de viagem, cartão de telefonia, passes de trem, aluguel de carros no Brasil e no exterior, cruzeiros, reservas on-line e serviço de lua de mel. O empresário entrevistado, possui 35 anos e graduação em Ciências Contábeis. As inovações adotadas na Agência 2 incluíram os quatro tipos de inovação propostos na classificação da OCDE (2005), inovações de serviço, processo, organizacional e de marketing. No que se refere às inovações de serviço adotadas em na agência, o empreendedor destacou os pacotes de lua de mel, nos quais a agência se tornou especialista. Esse novo serviço inclui pacotes especiais para recém-casados e atendimento personalizado, um serviço novo oferecido são os pacotes específicos para lua de mel, segundo o entrevistado um nicho de mercado 
novo com serviço diferenciado.

Outro serviço novo na agência é a venda de pacotes para Disney em grupos, pois anteriormente a empresa trabalhava apenas com a venda de pacotes individuais para esse destino. Ainda referente às inovações de serviço, o empreendedor relatou que passou a disponibilizar no site da agência o serviço de compra on-line, em que o cliente pode pesquisar preços de passagens aéreas e hotéis e comprar aquele que melhor se ajuste ao seu perfil sem precisar sair de casa. Além da compra on-line, também foi introduzido o serviço de atendimento on-line, que funciona de segunda a sexta em horário comercial e permite que o cliente tire suas dúvidas em relação a determinados destinos e preços, solicite orçamentos, ou marque um horário para atendimento presencial na agência. No que se refere às inovações de processo adotadas na agência, o empreendedor destacou apenas uma inovação que ocorreu no processo de vendas, por meio da aquisição de um sistema.

O terceiro tipo de inovação analisado refere-se às inovações organizacionais introduzidas na agência, inicialmente, mudanças ocorreram nas reuniões da empresa, que, antigamente, não tinham periodicidade definida e visavam apenas discutir problemas e fazer reclamações com os funcionários, atualmente, com as inovações adotadas, as reuniões ocorrem quinzenalmente e têm como objetivo principal a troca de conhecimentos entre os participantes. Outra inovação organizacional refere-se à tentativa de descentralização da gestão, pois tudo era demasiadamente concentrado no empreendedor.

O último aspecto analisado no caso da Agência 2 refere-se às inovações de marketing, a agência passou a divulgar seus serviços no guia Casar-se, pois diante do novo serviço foi necessário implantar uma divulgação específica para o público a que o serviço se destinava. Outra inovação de marketing foi à modernização do site, que ganhou um novo layout, tornando o acesso a ele mais simples. Ainda no campo das inovações de marketing, por meio da técnica de observação, verificou-se que a empresa está utilizando as diversas redes sociais, como o Facebook, Twitter, fanpage e Instagram para divulgar a agência. Nessas redes sociais, são divulgados os serviços oferecidos pela agência, além de promoções de passagens, pacotes de viagens e divulgação de alguns destinos.

A ideia para começar a utilizar as redes sociais, segundo o empreendedor, surgiu a partir da observação de diversas empresas, que estão utilizando maciçamente as redes socais para divulgação: "Eu comecei a observar o uso de diversas empresas das redes sociais, não só as agências de viagem, mas as empresas de um modo geral, porque é uma forma gratuita de divulgação, e que às vezes gera mais resultado do que uma propaganda na televisão". (informação verbal). Foi destacada ainda como inovação de marketing a implantação de um cartão fidelidade para os clientes corporativos, que proporcionará a estes a obtenção de descontos ou ainda a retirada de passagens ou hospedagem gratuitas. Por fim, o entrevistado afirmou que está adotando uma nova estratégia de marketing para divulgar o serviço de viagens em grupos para Disney, que inclui a distribuição de panfletos com pessoas fantasiadas de personagens da Disney, como o Mickey e a Minnie.

O último caso analisado nesse estudo é o da Agência de Viagens, a Agência 3 foi fundada no ano 1992, em relação aos serviços prestados, pode-se destacar excursões, cruzeiros, viagens de trem, viagens de ônibus, passagens aéreas, reserva de hotéis, aluguel de veículos e serviço de receptivo, a proprietária entrevista, possui 43 anos e nível superior em Comércio Exterior. As inovações implementadas no caso da Agência 3 incluíram inovações de serviço, de processo, organizacional e de marketing, conforme classificação proposta pela OCDE (2005). Em relação às inovações de serviço implementadas na agência nos últimos cinco anos, a partir da análise de folders disponibilizados na agência, verificou-se que, recentemente, foi implantada uma sala vip no aeroporto. Questionado sobre essa inovação, a empresária afirmou que a criação da sala vip no aeroporto tem como objetivo oferecer mais conforto aos clientes da agência, para que possam esperar pelo voo com maior tranquilidade. Outro novo serviço implantado na agência é o check in antecipado, que possibilita ao cliente da agência realizar o check in na loja do aeroporto, sem ter que enfrentar as longas filas dos balcões das companhias aéreas. A empreendedora destacou também como inovação de serviço a implantação do "serviço despertador", em que o cliente solicita o horário que quer ser acordado no dia de sua viagem, e um dos funcionários da loja do aeroporto telefona para o cliente para acordá-lo.

Ainda no que se refere às inovações de serviço, foi criada uma loja virtual no site da agência que possibilita aos clientes realizarem suas compras sem a necessidade de se deslocar para a agência. Na loja virtual, o cliente pode pesquisar e comprar rapidamente passagens aéreas e realizar reserva em hotéis nacionais e internacionais. Além da loja virtual, a empreendedora relatou ainda que no site da agência foi criado um espaço para os clientes, que permite que eles acompanhem todas as compras realizadas na agência: "Além da loja virtual, passamos a oferecer para nossos clientes a possibilidade de acessar pelo site da agência um relatório com todas as compras já realizadas por ele aqui na agência”. (in $\neg$ formação verbal). Ainda como inovação de serviço a disponibilização de um novo tipo de pacote de viagem: os pacotes para shows que acontecem fora do Estado, como por exemplo, o Rock in Rio, entre outros eventos de grande porte, esse novo serviço inclui passagens, hospedagem e transfer do hotel para o local do show. Por fim, a empresária afirmou que foi implantado o serviço "ligue grátis", em que o 
http://www.revista.ufpe.br/gestaoorg

cliente pode ligar gratuitamente de qualquer parte do mundo para solicitar suporte à agência.

Quando questionada acerca das inovações organizacionais implementadas na agência, a empresária afirmou que uma das inovações introduzidas nos últimos anos foi o processo de descentralização da gestão. A departamentalização foi outra inovação organizacional implementada na agência. Segundo a empreendedora, antigamente, as consultoras de venda, além de realizarem as vendas, faziam também o marketing, e havia apenas um setor administrativo geral que cuidava de toda administração. Hoje, entretanto, a agência está dividida em setores, como: financeiro, vendas, comercial e marketing, e cada um desses setores tem um supervisor responsável pela coordenação do setor. A empresária ressaltou que a agência está implantando um sistema de gestão de qualidade para adquirir a certificação da norma ISO 9001, estão sendo feitas uma série de adequações para que a empresa se enquadre nas especificações exigidas pela norma. Por fim, o último tópico analisado refere-se às inovações de marketing onde foi implementado pesquisa de satisfação realizada com os clientes da agência, outra inovação de marketing se refere à utilização de novas mídias, como o Facebook e o Twitter para divulgar os pacotes, promoções e novidades da agência.

\subsection{Comparação entre os casos}

$\mathrm{Na}$ análise comparativa, buscou-se enfatizar as similitudes e diferenças entre os casos analisados. Além disso, buscou-se, sempre que possível, comparar os resultados deste estudo com os estudos apresentados na fundamentação teórica. Os empresários entrevistados e as agências objeto deste estudo serão identificados nessa análise, respectivamente, por: E1, E2, E3 e A1, A2, A3.

Em relação à inovação de serviços, observou-se no caso da Agência A1, além das alterações no processo de vendas, houve também inovação no processo de atendimento dos clientes. O empreendedor E1 explicou que o atendimento na agência agora é feito de maneira setorizada, de modo que existem consultores especializados para o atendimento a clientes corporativos e outros para pessoa física. Resultado que é corroborado por Gorni, Dreher e Machado (2009) seu estudo verificaram que a adoção de novas formas de atender clientes é uma inovação de processo comum entre agências de viagem. Por fim, convém destacar as inovações de serviço implementadas na Agência 3, que envolveram o serviço de check in antecipado, o "serviço despertador", e o "ligue grátis". Referente às inovações organizacionais implementadas pelas empresas pesquisadas, foram destacadas pelos empreendedores inovações como descentralização da gestão, adoção de novas estruturas organizacionais e alterações no sistema de reuniões. No caso da Agência A3, o empresário E3 destacou que está implantando um sistema de gestão de qualidade para adquirir a certificação da norma ISO 9001. Álvares e Lourenço (2011) destacaram que os programas de certificação são uma inovação que gera impactos bastante positivos para os destinos turísticos, na medida em que buscam definir padrões de competência das empresas e/ou dos profissionais, elevando a qualidade dos serviços oferecidos.

No que se refere às inovações de marketing implementadas pelas empresas analisadas, foram destacadas inovações como a utilização das redes sociais para divulgação, reformulação de sites, adoção de novas estratégias promocionais e utilização de novas mídias de divulgação. Em relação à utilização de redes sociais para divulgação das empresas, esse tipo de inovação de marketing também foi identificado no estudo de Flores, Cavalcante e Raye (2012) em que se verificou que as redes sociais aparecem com uso bastante significativo nas empresas de turismo, o que, segundo os autores, é um bom resultado, pois, atualmente, mais de $80 \%$ dos "internautas" brasileiros estão conectados a alguma rede social.

Ainda no campo das inovações de marketing, verificou-se que foram adotadas novas estratégias promocionais, estas incluíram a criação de festival de prêmios, com o sorteio de brindes (caso da Agência A1), e o desenvolvimento de ações promocionais exclusivas para clientes corporativos, com a criação de um cartão fidelidade, que proporciona a obtenção de descontos ou ainda a retirada de passagens ou hospedagem gratuitas (Agência A2). Esses resultados também foram encontrados no estudo de Pires (2010), que verificou que empresas turísticas estão investindo nos programas de fidelidade ou de pontuação, em que cada vez que o cliente efetua uma compra, é maior a possibilidade de ganhar passagens ou de se obter garantias e premiações.

No que se refere às novas mídias de divulgação, no caso da Agência A1, é a televisão, com vistas a alcançar o maior público possível. No caso da Agência A2, foram adotadas novas estratégias de divulgação voltadas para públicos específicos, como a divulgação dos serviços de lua de mel no guia e workshop Casar-se, para atingir noivas, e distribuição de panfletos com pessoas fantasiadas de personagens da Disney, para atingir o público que deseja viajar em grupos para Disney.

\section{Considerações Finais}

As atividades turísticas são consideradas por muitos pesquisadores como uma indústria moderadamente inovadora, questões relativas à inovação no setor turístico vêm ganhando cada vez mais espaço (HALL, 2009) 
pois, conforme destacam Sundbo, Orfila-Sintes e Sorensen (2007) o ato de inovar em turismo é uma condição essencial para a sobrevivência das empresas que atuam em um ambiente extremamente competitivo e em contínua transformação. Muitos estudiosos (Fitzsimmons; Fitzsimmons, 2005; Moraes, 2007; Flores; Cavalcante; Raye, 2012) destacaram o uso das tecnologias de informação (TI) como uma inovação comum no setor turístico, em especial, nas agências de viagens.

No presente estudo essa constatação é verificada, na medida em que em todas as agências foram implementados serviços inovadores por intermédio da internet, como atendimento e compra on-line. Além disso, especificamente no site da Agência 1, estão sendo oferecidos serviços diferenciados, como pesquisa de preços de passagens aéreas e tarifas de hotéis, conversão de câmbio, fuso horário e minidicionário, em que o cliente pode visualizar algumas expressões básicas em vários idiomas. Os empreendedores relataram que a oferta de serviços através da internet se tornou uma inovação quase que obrigatória, pois houve uma mudança no perfil dos consumidores, que, atualmente, querem comprar os serviços turísticos sem necessitar se deslocar.

Foram verificados ainda outros serviços inovadores nas agências pesquisadas, como criação de salas vip no aeroporto, a fim de oferecer suporte aos clientes nos momentos anteriores ao embarque e novos pacotes de viagem para públicos específicos, como, por exemplo, pacotes especiais para lua de mel e para viagens em grupo. Resultado similar foi encontrado na pesquisa de Gorni, Dreher e Machado (2009), em que se observou que as agências de viagem estão inovando por meio da disponibilização de novos pacotes e roteiros turísticos para seus clientes.

Referente às inovações de processo, foi possível verificar que em todas as agências de viagens foram adotadas inovações no processo de vendas, as inovações ocorreram por meio da aquisição de softwares que tornaram o processo mais prático e rápido. Finalmente, vale destacar, neste estudo, a preocupação com a adoção de serviços inovadores em empresas turísticas que sirvam como diferencial em relação aos concorrentes, uma vez que o setor está cada vez mais competitivo, exigindo dos empreendedores uma atitude proativa na adoção de novos serviços.

\section{Referências}

ÁLVARES, D.; LOURENÇO, J. Inovações com incidência direta na atividade turística: uma análise dos destinos de Ouro Preto-MG e Salvador-BA. Revista de Cultura e Turismo, v. 5, p. 33-43, 2011.

ALVES, S. Estratégias de inovação em mercados maduros: um olhar a partir do segmento de serviços de hotelaria. In: SEMINÁRIO DA ASSOCIAÇÃO NACIONAL PESQUISA E PÓS-GRADUAÇÃO EM TURISMO, 8., 2011, Balneário Camboriú, 2011. Anais... Balneário Camboriú, 2011.

BENI, M. C. Globalização do turismo: megatendências do setor e a realidade brasileira. 2. ed. São Paulo: Aleph, 2003.

CHRISTENSEN, C. O dilema da inovação. São Paulo: Makron Books, 2001.

CRESWELL, J. W. Research Design: qualitative, quantitative and mixed methods approaches. 3. ed. Thousand Oaks: Sage, 2009.

EMBRATUR. Brasil é o $6^{\mathbf{0}}$ no mundo em economia do Turismo. Brasília, 2014. Disponível em: <http://www.embratur.gov.br/piembratur/opencms/salaImprensa/ noticias/arquivos/Brasil_e_o_6_no_mundo_em_economia_do_Turismo.html>. Acesso em: 15 out. 2014.

FIRMINO, M. B. Turismo: organização e gestão. Lisboa: Escolar Editora, 2007.

FITZSIMMONS, J. A.; FITZSIMMONS, M. J. Administração de serviços: operações, estratégia e tecnologia da informação. 4. ed. Porto Alegre: Bookman, 2005.

FLORES, L. C. da S.; CAVALCANTE, L. de S.; RAYE, R. L. Marketing turístico: estudo sobre o uso da tecnologia da informação e comunicação nas agências de viagens e turismo de Balneário Camboriú (SC, Brasil).

Revista Brasileira de Pesquisa em Turismo, São Paulo, v. 6, n. 3, p. 322-339, set./dez. 2012.

GALBRAITH, J. K. American capitalism: the concept of countervailing power. Boston: Houghton Mifflin Company, 1956.

GORNI, P. M.; DREHER, M. T.; MACHADO, D. P. N. Inovação em serviços turísticos: a percepção desse processo em agências de viagens. Revista acadêmica Observatório de Inovação do Turismo, v. 4, 2009.

HALL, C. M. Innovation and tourism policy in Australia and New Zealand: never the twain shall meet? Journal of Policy Research in Tourism, Leisure and Events, v. 1, n. 1, p. 2-18, 2009.

HJALAGER, A. M. A review of innovation research in tourism. Tourism Management, v. 31, n. 1, 2010. 
LAFORET, S.; TANN, J. Innovative characteristics of small manufacturing firms. Journal of Small Business and Enterprise Development, v. 13, n. 3, p. 363- 380, 2006.

MATTSSON, J.; SUNDBO, J.; JENSEN, C. F. Innovation systems in tourism: the roles of attractors and scenetakers. Industry and Innovation, Sydney, v. 12, n. 3, p. 357, 2005.

MORAES, A. G. Tecnologia de informação nas agências de turismo: uma análise de como as agências estão utilizando esse recurso para se manter competitiva. Revista de Turismo y Patrimonio Cultural, v. 5, p. 163173, 2007.

NATÁRIO, M. M.; COUTO, J. P.; SOUZA, M. H. C. Grau de inovação das pequenas e médias empresas nas regiões periféricas da guarda e açores. Working Paper, Portugal, n. 10, dez. 2010.

ORGANIZAÇÃO MUNDIAL DO TURISMO. Relatório Anual - Um ano de recuperação. 2012. Disponível em: 〈http://www.eunwto.org/content/ p201q5985713q440/fulltext.pdf?page=1>. Acesso em: 12 abr. 2014.

ORGANIZAÇÃO PARA A COOPERAÇÃO E DESENVOLVIMENTO ECONÔMICO. Manual de Oslo: Proposta de diretrizes para coleta e interpretação de dados sobre inovação tecnológica. Tradução Finep, 2005.

OTTENBACHER, M. C. Innovation management in the hospitality industry: different strategies for achieving success. Journal of Hospitality \& Tourism Research, v. 31, n. 4, p. 431-454, 2007.

PANOSSO NETTO, A.; MAZARO, R. M. Competitividade e inovação em turismo. In: BENI, M. C. (Org.). Políticas Públicas e Planejamento Estratégico em Clusters de Turismo. São Paulo: Manole, 2011.

PIRES, L. C. Análise dos impactos da tecnologia de informação e comunicação para o turismo. Observatório de Inovação do Turismo, v. 5, n. 4, dez. 2010.

RUSCHMANN, D.; SOLHA, K. T. Turismo: uma visão empresarial. Barueri: Manole, 2003.

SCHUMPETER, J. A. Teoria do desenvolvimento econômico: uma investigação sobre lucros, capital, crédito, juro e o ciclo econômico. São Paulo: Abril Cultural, 1982.

SUNDBO, J.; ORFILA-SINTES, F.; SØRENSEN, F. The innovative behavior of tourism firms - Comparative studies of Denmark and Spain. Research Policy, v. 36, p. 88-106, 2007.

TIDD, J.; BESSANT, J.; PAVITT, K. Gestão da Inovação. Porto Alegre: Bookman, 2008.

WEIDENFELD, A.; WILLIAMS, A. M.; BUTLER, R. W. Knowledge transfer and innovation among attractions. Annals of Tourism Research, v. 37, n. 3, p. 604-626, 2010.

YIN, R. K. Estudo de caso: planejamento e método. 2. ed. Porto Alegre: Bookman, 2001.

ZORTEA-JOHNSTON, E.; DARROCH, J.; MATEAR, S. Business orientations and innovation in small and medium sized enterprises. Int Entrep Manag J., v. 8, p. 145-164, 2011. 